\title{
Biodegradation of Ochratoxin A by Fungi Isolated from Grapes
}

\author{
Luís Abrunhosa, Rita Serra, ANd Armando VenÂNCiO* \\ Centro de Engenharia Biológica-IBQF, Universidade do Minho, Campus de Gualtar,
} 4710-057 Braga, Portugal

\begin{abstract}
Ochratoxin A is a mycotoxin present in several food products for which levels should be reduced. Chemical, physical, and biological methods have been proposed for the detoxification of mycotoxins, biological methods being the more promising ones. In this report, filamentous fungi isolated from Portuguese grapes were assessed for ochratoxin A degradation capabilities. It was observed that 51 of the 76 tested strains, predominantly aspergillus species, were able to degrade more than $80 \%$ of ochratoxin $A$ added to the culture medium and that the most potent species (more than $95 \%$ of initial amount) were the black aspergilli, $A$. clavatus, $A$. ochraceus, $A$. versicolor, and $A$. wentii. Other fungi frequently isolated from grapes, such as Alternaria, Botrytis, Cladosporium, and Penicillium, also showed significant degradation capabilities. It was observed that the compounds obtained from the degradation of ochratoxin A by black aspergilli and by $A$. ochraceus and $A$. wentii strains were different.
\end{abstract}

KEYWORDS: Alternaria; Aspergillus; Botrytis; Cladosporium; detoxification; grapes; ochratoxin A; Penicillium; wine

\section{INTRODUCTION}

Ochratoxin A is a 7-carboxy-5-chloro-8-hydroxy-3,4-dihydro$3 R$-methylisocoumarin, linked through its 7-carboxy group to $\mathrm{L}-\beta$-phenylalanine by an amide bond (1). Ochratoxin $\mathrm{A}$ is a mycotoxin with nephrotoxic, hepatotoxic, teratogenic, carcinogenic, and immunosuppressive properties (2). Several fungi have been reported as ochratoxigenic, including Aspergillus alliaceus, A. carbonarius, some strains of the A. niger aggregate, $A$. ochraceus, and Penicillium verrucosum. Others, such as Aspergillus albertensis, A. auricomus, A. awamori, A. foetidus, A. sclerotiorum, A. terreus, and A. wentii have also been reported as ochratoxin A producers, but their production is not yet well established $(3,4)$.

Ochratoxin A is frequently detected in food products, such as cereals (5), coffee (6), dried vine fruits (7), beer (8), and wine (9). In the particular case of wine, several efforts have been made to establish a correlation between ochratoxin A presence and fungi isolated from grapes. A. carbonarius and A. niger aggregate strains are now generally incriminated as primarily responsible for ochratoxin A production in grapes and derived products $(10-12)$. It is generally accepted that ochratoxin A levels in food products needs to be reduced as low as technologically possible (13). Several physical and chemical methods have been proposed for the removal of mycotoxins from foods and feeds (14). However, few of these have practical application. One example is the removal of ochratoxin A from wines by adsorption with fining agents. Studies showed that most of the fining agents have little effect on the removal of ochratoxin A and that in many cases the quality of wines is

* Corresponding author. Telephone: +351.253604413. Fax: +351.253678986. E-mail: avenan@deb.uminho.pt. severely damaged $(15,16)$. Therefore, microbiological methods may present a good alternative in mycotoxin detoxification. The use of enzymes is far more convenient than the chemical or physical detoxification methods, since it is substrate specific (17).

Several reports of ochratoxin A biodegradation have been published. Cell cultures of wheat, maize, tomato, soybean, sweet potato tubers, and other plants completely transform ochratoxin A into a number of other products (18). Streptococcus salivarius subsp. thermophilus, Bifidobacterium bifidum, and yogurt bacteria have completely reduced ochratoxin A levels in milk samples containing 0.05 and $0.1 \mathrm{mg} / \mathrm{L}$; Lactobacillus delbrueckii subsp. bulgaricus completely reduced ochratoxin A level in milk samples with $0.5 \mathrm{mg} / \mathrm{L}$ (19). Some strains of A. fumigatus, A. japonicus, and A. niger have also been reported to be able to degrade ochratoxin A to less toxic products such as ochratoxin $\alpha(20)$.

This study reports the capacity of ochratoxigenic and nonochratoxigenic filamentous fungi isolated from Portuguese grapes to degrade ochratoxin A to less toxic compounds.

\section{MATERIALS AND METHODS}

Filamentous Fungi. Seventy-six strains were selected among filamentous fungi isolated from Portuguese grapes, for which ochratoxigenic ability was previously assessed according to the method of Bragulat et al. (10). Strains were set in three groups: 37 black aspergilli (A. carbonarius, A. ellipticus, A. foetidus, A. japonicus, and A. niger aggregate); 25 other Aspergillus strains; and 14 other genera. All the selected strains are preserved in the Micoteca da Universidade do Minho culture collection-MUM (21).

Media and Growth Conditions. Strains were first grown in malt extract agar (Blakeslee formula) for 7 days in the dark at $25{ }^{\circ} \mathrm{C}$ for inoculum generation. A spore suspension was collected and inoculated 
Table 1

\begin{tabular}{|c|c|c|c|c|c|}
\hline \multirow[b]{2}{*}{ species } & \multicolumn{5}{|c|}{ degradation } \\
\hline & $0 \%$ & $1-50 \%$ & $50-80 \%$ & $80-95 \%$ & $95-100 \%$ \\
\hline \multicolumn{6}{|c|}{ a. Degradation of Ochratoxin A by Aspergilli Strains } \\
\hline \multicolumn{6}{|l|}{ black aspergilli } \\
\hline A. carbonarius & & & & & 1 \\
\hline A. carbonarius (ochratoxigenic) & & & 2 & 2 & 1 \\
\hline A. ellipticus & & & & & 2 \\
\hline A. foetidus & & & & & 1 \\
\hline A. japonicus & & & & & 1 \\
\hline A. niger aggregate & & & & 3 & 19 \\
\hline A. niger aggregate (ochratoxigenic) & & & & 1 & 4 \\
\hline \multicolumn{6}{|l|}{ other aspergilli } \\
\hline A. alliaceus & 1 & & & & \\
\hline A. clavatus & & & & 1 & \\
\hline A. flavus & & 1 & 2 & & \\
\hline A. fumigatus & & & 1 & 4 & \\
\hline A. ochraceus & & & & & 1 \\
\hline A. ochraceus (ochratoxigenic) & 1 & & & & \\
\hline A. terreus & & 1 & 2 & & \\
\hline A. ustus & & 2 & 1 & & \\
\hline A. versicolor & & & & & 3 \\
\hline A. wentii & & & 1 & 1 & 2 \\
\hline \multicolumn{6}{|c|}{ b. Degradation of Ochratoxin A by Other Genera } \\
\hline other genera & & & & & \\
\hline Alternaria sp. & & & 1 & & \\
\hline Aureobasidium pullulans & & 1 & & & \\
\hline Botrytis cinerea & & & 1 & & \\
\hline Cladosporium sp. & & & & 1 & \\
\hline Emericella nidulans & & & 1 & & \\
\hline Mucor sp. & & 1 & & & \\
\hline Penicillium aurantiogriseum & & & & 4 & \\
\hline Penicillium spinulosum & & & & 1 & \\
\hline Rhizopus sp. & & 1 & & & \\
\hline Trichoderma sp. & & 1 & & & \\
\hline Trichothecium roseum & & 1 & & & \\
\hline
\end{tabular}

in $5 \mathrm{~mL}$ of yeast extract sucrose medium supplemented with ochratoxin A (YES-Difco+ochratoxin A: 2\% of yeast extract from Difco, 15\% of sucrose, and $1 \mu \mathrm{g} / \mathrm{mL}$ of ochratoxin A). A control for each strain was also inoculated in $5 \mathrm{~mL}$ of yeast extract sucrose medium (YESDifco: $2 \%$ of yeast extract from Difco and $15 \%$ of sucrose). Inoculated flasks were incubated slanted to increase superficial area, for 6 days, in the dark, at $25^{\circ} \mathrm{C}$.

Ochratoxin A Extraction. After incubation, fungal colonies were removed from the remaining medium. The medium was acidified with $1 \mathrm{~mL}$ of $2 \mathrm{M} \mathrm{HCl}$ and extracted twice with $5 \mathrm{~mL}$ of chloroform. This extract was evaporated to dryness at $50{ }^{\circ} \mathrm{C}$ with a gentle stream of nitrogen, and the dried extract was stored at $4{ }^{\circ} \mathrm{C}$ until HPLC analysis. The recovery of the extraction process $(85.9 \pm 0.6 \%)$ was determined by extracting three control samples of fresh YES-Difco+ochratoxin A medium $(5 \mathrm{~mL})$. A control of YES-Difco medium $(5 \mathrm{~mL})$ was also extracted to confirm the absence of ochratoxin A from the medium ingredients.

Ochratoxin A Detection and Quantification. Ochratoxin A was detected and quantified by high-performance liquid chromatography. The HPLC apparatus consisted of a Knauer K-1001 pump equipped with a Jasco FP-920 fluorescence detector $\left(\lambda_{\mathrm{ex}}=333 \mathrm{~nm} ; \lambda_{\mathrm{em}}=460\right.$ $\mathrm{nm})$ and a Borwin version 1.21.60 acquisition data system. The analytical column was a $250 \times 4.6 \mathrm{~mm}, 5 \mu \mathrm{m}, \mathrm{C}_{18}$ reversed-phase Waters Spherisorb ODS2, fitted with a precolumn with the same stationary phase. The mobile phase consisted of a mixture of HPLC grade acetonitrile/water/acetic acid (99/99/2, v/v/v), filtered with a 0.2$\mu \mathrm{m}$ GHP membrane filter (Gelman) and degassed. The mobile phase flow rate was set to $1.0 \mathrm{~mL} / \mathrm{min}$ and the column temperature to $30^{\circ} \mathrm{C}$. The dried extracts were dissolved in $1 \mathrm{~mL}$ of mobile phase and filtered with a $0.45-\mu \mathrm{m}$ Acrodisc GHP membrane filter (Gelman). Injections were done with a manual Knauer injection valve equipped with a 10$\mu \mathrm{L}$ loop. A calibration curve, which was regularly checked, was prepared with three ochratoxin A standards (Sigma). Ochratoxin A was identified by comparing retention times of peak samples with standards. Quantification was done by measuring peak height and comparing it with the respective calibration curve. The ochratoxin A degradation
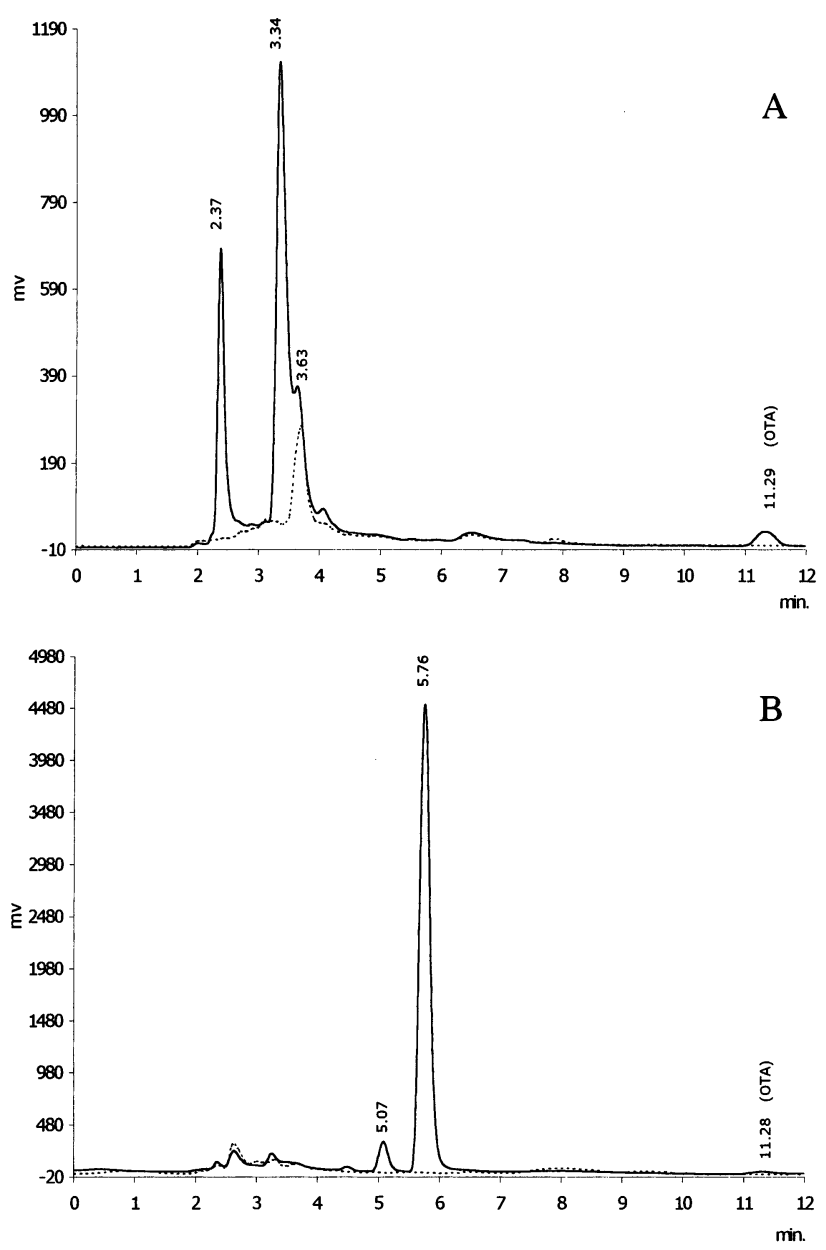

Figure 1. Compounds resulting from degradation of ochratoxin $A$ by $(A)$ black aspergilli and (B) $A$. ochraceus and $A$. wentii strains (-, YESDifco+ochratoxin A medium; $\cdots$, YES-Difco medium).

percentage was calculated relative to the recovery mean value $(85.9 \%)$ as the initial amount present in media.

Standards of ochratoxin $\alpha$ were prepared by acid or by enzymatic hydrolysis of ochratoxin A. Acid hydrolysis was performed as described by van der Merwe et al. (1). Enzymatic hydrolysis was performed with carboxypeptidase A (EC 3.4.17.1) from bovine pancreas (Sigma, type II-PMSF). Ochratoxin A was dissolved in $1 \mathrm{~mL}$ of buffered solution $(0.025 \mathrm{M}$ Tris- $\mathrm{HCl}, 0.5 \mathrm{M} \mathrm{NaCl}, \mathrm{pH} 7.5)$ and $20 \mu \mathrm{L}$ of enzyme solution was added. Total degradation was observed after 2 days of incubation at room temperature.

\section{RESULTS AND DISCUSSION}

As shown in Table 1, most of the tested strains degraded ochratoxin A while growing on the selected medium: 51 strains (67\% of tested strains) were able to degrade more than $80 \%$ of ochratoxin A added to YES-Difco medium. These 51 strains belong to 13 different species from three genera: Aspergillus (10 species), Cladosporium (one species), and Penicillium (two species).

Most aspergilli extensively degraded ochratoxin A (>95\%). Black aspergilli, A. clavatus, A. ochraceus, A. versicolor, and $A$. wentii were the species most effective in this regard. In a similar study, Varga and co-workers (20) have reported the degradation of ochratoxin A by some strains of A. fumigatus, A. japonicus, and A. niger. In our study we observed that other species also have ochratoxin A degradation capability. The differences observed between these two studies may be due to the ochratoxin A detection method employed by Varga et al. 

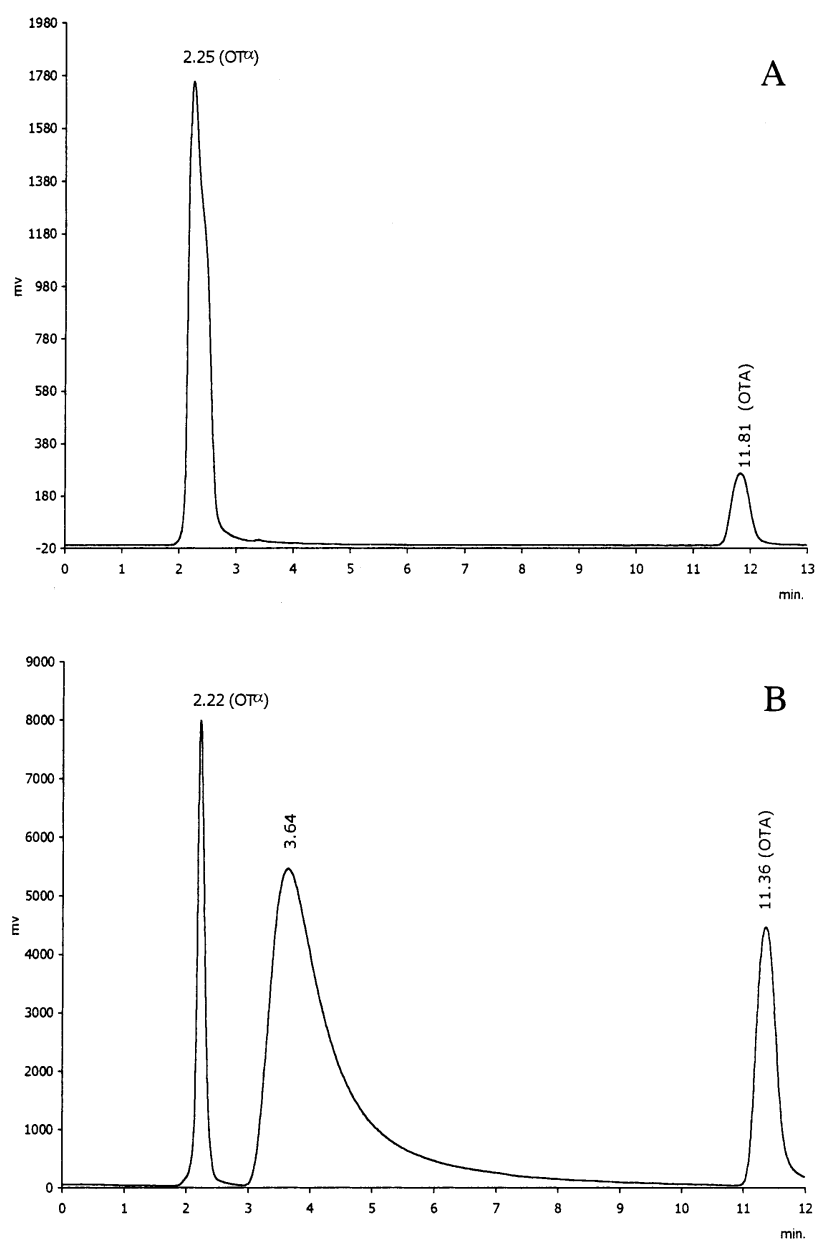

Figure 2. (A) Ochratoxin $\alpha$ resulting from acid hydrolysis of ochratoxin A. (B) Compounds resulting from degradation of ochratoxin $A$ by carboxypeptidase $\mathrm{A}$.

(20). These authors used a TLC method, which is less sensitive to variation in ochratoxin A amounts than the HPLC method used in our study.

Penicillium strains and the Cladosporium strain tested degraded more than $80 \%$ of the initial ochratoxin A. But other strains, such as Alternaria sp., Botrytis cinerea, and Emericella nidulans, degraded more than $50 \%$ of the initial ochratoxin A. All the remaining strains showed less capability to degrade ochratoxin A.

Ochratoxin A Degradation by Black Aspergilli. Thirtyfive black aspergilli (95\% of those tested) were able to degrade more than $80 \%$ of initial ochratoxin A amount, and even some ochratoxigenic strains degraded that amount of the mycotoxin (Table 1a). The other two black aspergilli are ochratoxigenic A. carbonarius and are the best producers of ochratoxin A among the black aspergilli tested. Their lesser degradation capability may be due to the production of a greater amount of ochratoxin A in the culture medium.

The products of ochratoxin A degradation were the same in all tested species of black aspergilli. Two compounds resulted from ochratoxin A degradation by these strains (Figure 1A). One of these compounds had a retention time close to the ochratoxin $\alpha$ standard obtained by acid hydrolysis (Figure 2A), but both of these compounds were obtained when ochratoxin A was degraded with carboxypeptidase A (Figure 2B). We conclude that a carboxypeptidase may be involved in the degradation of ochratoxin A by these strains.
Ochratoxin A Degradation by A. alliaceus, A. ochraceus, and A. wentii. The Aspergillus alliaceus, A. ochraceus, and A. wentii strains tested behaved differently from the black aspergilli. The two ochratoxigenic strains (one A. alliaceus and one $A$. ochraceus) produced large amounts of ochratoxin A. Therefore, the mycotoxin detected after the 6 days incubation exceeded the initial amount added. These strains either do not degrade ochratoxin A or do it at a slower rate than they produce it.

The nonochratoxigenic A. ochraceus (one strain) and A. wentii (four strains) degraded ochratoxin A in large amounts, yielding reaction products that are not produced during the degradation by the black aspergilli (Figure 1B). The degradation pathway of ochratoxin A in these two species differs from the one observed in the black aspergilli.

In this study, it is clearly observed that the fungi most frequently isolated from grapes, Alternaria, Aspergillus, Botrytis, Cladosporium, and Penicillium (10,22), have significant ochratoxin A degradation capabilities, regardless of being ochratoxigenic or not. This capacity may be present in grapes and should be taken into account when trying to relate the ochratoxin A presence in grapes with their mycoflora. When analyzing the ochratoxin A degradation products, it was found that all the black aspergilli produced the same products and that $A$. ochraceus and $A$. wentii exhibited a different degradation pathway. Different degradation enzymes and pathways may be involved in the degradation of ochratoxin $\mathrm{A}$ by these species.

\section{SAFETY}

Ochratoxin A is a toxic compound that needs to be manipulated with care and with appropriate safety precautions. Decontamination procedures for laboratory wastes have been reported by the International Agency for Research on Cancer (IARC) (23) and were employed throughout this experimental work.

\section{ACKNOWLEDGMENT}

Received for review June 19, 2002. Revised manuscript received September 17, 2002. Accepted September 19, 2002. We gratefully acknowledge the support of the EC, Quality of Life Program (QoL), Key Action 1 (KA1) on Food, Nutrition and Health; contract number QLK1-CT-2001-01761-Wine-Ochra Risk. R.S. was supported by grant SFRH/ BD/1436/2000 from Fundação para a Ciência e Tecnologia.

\section{LITERATURE CITED}

(1) van der Merwe, K. J.; Steyn, P. S.; Fourie, L. Mycotoxins. Part II. The constitution of ochratoxin A, B, and C, metabolites of Aspergillus ochraceus Wilh. J. Chem. Soc. 1965, 7083-7088.

(2) Størmer, F. C. Ochratoxin A-A mycotoxin of concern. In Handbook of applied mycology. Vol: 5. Mycotoxins in ecological systems; Bhatnager, D., Lillehoj, E. B., Arora, D. K., Eds.; Marcel Dekker: New York, 1992; pp 403-432.

(3) Varga, J.; Kevei, É.; Rinyu, E.; Téren, J.; Kozakiewicz, Z. Ochratoxin production by Aspergillus species. Appl. Environ. Microbiol. 1996, 62, 4461-4464.

(4) Téren, J.; Varga, J.; Hamari, Z.; Rinyu, E.; Kevei, F. Immunochemical detection of ochratoxin A in black Aspergillus strains. Mycopathologia 1996, 134, 171-176.

(5) Jorgensen, K.; Rasmussen, G.; Thorup, I. Ochratoxin A in Danish cereals 1986-1992 and daily intake by the Danish population. Food Addit. Contam. 1996, 13, 95-104.

(6) Pittet, A.; Tornare, D.; Huggett, A.; Viani, R. Liquid chromatographic determination of ochratoxin $\mathrm{A}$ in pure and adulterated soluble coffee using an immunoaffinity column cleanup procedure. J. Agric. Food Chem. 1996, 44, 3564-3569. 
(7) MacDonald, S.; Wilson, P.; Barnes, K.; Damant, A.; Massey, R.; Mortby, E.; Shepherd, M. J. Ochratoxin A in dried vine fruit: Method development and survey. Food Addit. Contam. 1999, 16, 253-260.

(8) Visconti, A.; Pascale, M.; Centonze, G. Determination of ochratoxin A in domestic and imported beers in Italy by immunoaffinity clean-up and liquid chromatography. J. Chromatogr. A 2000, 888, 321-326.

(9) Zimmerli, B.; Dick, R. Determination of ochratoxin A at the ppt level in human blood, serum, milk and some foodstuffs by high-performance liquid chromatography with enhanced fluorescence detection and immunoaffinity column cleanup: Methodology and Swiss data. J. Chromatogr. B 1995, 666, 85-99.

(10) Serra, R.; Kozakiewicz, Z.; Lima, N.; Venâncio, A. Isolation of filamentous fungi from grapes and study of ochratoxin A production in grape and must by indigenous Aspergillus. Proceedings: Bioactive Fungal metabolites-impact and exploitation; Swansea, U.K., 2001; p 93.

(11) Cabañes, F. J.; Accensi, F.; Bragulat, M. R.; Abarca, M. L.; Castellá, G.; Minguez, S.; Pons, A. What is the source of ochratoxin A in wine? Int. J. Food Microbiol. 2002, 79, 213215.

(12) Sage, L.; Krivobok, S.; Delbos, E.; Seigle-Murandi, F.; Creppy, E. E. Fungal flora and ochratoxin A production in grapes and musts from France. J. Agric. Food Chem. 2002, 50, 1306-1311.

(13) Codex Committee on Food Additives and Contaminants. Revised position paper on ochratoxin A. 1997, CX/FAC 98/16.

(14) Sinha, K. K. Detoxification of Mycotoxins and Food Safety. In Mycotoxins in Agriculture and Food Safety; Sinha K. K., Bhatnagar D., Eds.; Marcel Dekker: New York, 1998; pp 381406.

(15) Castellari, M.; Versari, A.; Fabiani, A.; Parpinello, G. P.; Galassi,
S. Removal of ochratoxin A in red wines by means of adsorption treatments with commercial fining agents. J. Agric. Food Chem. 2001, 49, 3917-3921.

(16) Dumeau, F.; Trioné, D. Influence de différents traitments sur la concentration en ochratoxine A des vins rouges. Reveus Fr. CEnol. 2000, 95, 37-38.

(17) Liu, D.-L.; Yao, D. S.; Liang, Y.-Q.; Zhou, T.-H.; Song, Y.-P.; Zhao, L.; Ma, L. Production, purification and characterization of an intracellular aflatoxin-detoxifizyme from Armillariella tabescens (E-20). Food Chem. Toxicol. 2001, 39, 461-466.

(18) Karlovsky, P. Biological detoxification of fungal toxins and its use in plant breeding, feed and food production. Nat. Toxins 1999, 7, 1-23.

(19) Škrinjar, M.; Rašić, J. L.; Stojičić, V. Lowering of ochratoxin A level in milk by yoghurt bacteria and bifidobacteria. Folia Microbiol. 1996, 1, 26-28.

(20) Varga, J.; Rigó, K.; Téren, J. Degradation of ochratoxin A by Aspergillus species. Int. J. Food Microbiol. 2000, 59, 1-7.

(21) Santos, I. M.; Lima, N. Criteria followed in the establishment of a filamentous fungi culture collection-Micoteca da Universidade do Minho (MUM). World J. Microbiol. Biotechnol. 2001, $17,215-220$.

(22) Abrunhosa, L.; Paterson, R. R.; Kozakiewick, Z. Lima, N.; Venâncio, A. Mycotoxin production from fungi isolated from grapes. Lett. Appl. Microbiol. 2001, 32, 240-242.

(23) Castegnaro, M.; Barek, J.; Fremy, J. M.; Lafontaine, M.; Miraglia, M.; Sansone, E. B.; Telling, G. M. Laboratory decontamination and destruction of carcinogens in laboratory wastes: Some mycotoxins. IARC Scientific Publication no. 113; International Agency for Research on Cancer: Lyon, France, 1991; p 63.

JF025747I 